\title{
Research of Chinese View towards American Animation
}

\author{
Zhou Zhou1, Junhui Gao ${ }^{*}$ \\ ${ }^{1}$ Wuxi Big Bridge Academy, Wuxi, China \\ ${ }^{2}$ American and European International Study Center, Wuxi, China \\ Email: ^jhgao68@163.com
}

How to cite this paper: Zhou, Z., \& Gao, J. H. (2018). Research of Chinese View towards American Animation. Art and Design Review, 6, 141-147.

https://doi.org/10.4236/adr.2018.63014

Received: June 24, 2018

Accepted: August 5, 2018

Published: August 8, 2018

Copyright (c) 2018 by authors and Scientific Research Publishing Inc. This work is licensed under the Creative Commons Attribution International License (CC BY 4.0).

http://creativecommons.org/licenses/by/4.0/

\begin{abstract}
This article analyzes the Chinese people's understanding of American animation through questionnaires. There are 16 questions in the questionnaire, including three types. The first type is about the understanding and preference of animation images, companies, designers and so on. The second is the question of purchasing animation products, such as the purchase way, the consumption frequency, etc. The third type is about the questioners themselves. We collect the effective data from the questionnaire. First, we make statistics according to the options in the questionnaire, and further analyze the two types of questions, such as the understanding of the people of different ages towards the American animation company, the gender of the questioner and the preferable animation type, and so on.
\end{abstract}

\section{Keywords}

American Animation, Questionnaire, Chinese, Animated Figures, Artists, Cross Topic Analysis

\section{Introduction}

Both animation and comics originated from Europe and America, the Italian word "cartoon" in the 19th century refers to European comic books (dcfiff3juv, 2016).

$\mathrm{Xu}$ (2009) believes that the success of the American comic industry is inseparable from the intriguing content and entertaining effect of its works. The development of American animated film and TV shows a distinct characteristic after a long period of development. It is based on the plot, twists and turns, interesting scenes, vivid characters, fascinating music, colorful pictures, which were mostly warm colors. The plot ends with reunion, suits the taste of the vast ma- 
jority of the audience. Most of the cartoon images are exaggerated: big head, big eyes, big hands and big feet. It has become a widely used animation mode widely used by other countries in the world.

Shi \& Wang (2011) believe that American animation works usually have vivid and tortuous story plots, funny movements, vivid role images, exquisite and superb production techniques, perfect ending, and original music. At the same time, it also pays attention to portraying details, making the characters' action and psychological portrayal perfectly, making people feel comfortable. The characters or animals play a role as dramatic as possible, and become a model of learning of anime making for enthusiasts in various countries. The most exciting part of American film and TV animation films is that the development of the digital age, the continuous updating of the special effects technology, from the classic two-dimension to three-dimension to the IMAX screen, not only satisfies the high requirements of audience, but also achieved the transformation of its own technology.

Gao Wang thinks that as a hot industry in the world, animation is an industrial form to show creativity through animation and comic form. The development of this industry includes various forms of expansion, such as movies, newspapers and periodicals and the production established on the basis of modern information, as well as the derivative productions related to animation image. At present, after a long development, United States' animation industry has become one of its pillar industries, and the export of its animation products even overpasses some high-tech industries (Gao, 2015).

In the Silver Age of Comics, the comic book Superman could be sold over a million copies in one week worldwide. It's obvious to see that comics have a great influence on the public.

This article investigates the degree of and the interest in American animation by Chinese people of different ages. By analyzing different data and products and influences, we conclude the future development of American animation industry in China.

\section{Methods}

Our research is carry out by designing questionnaires, collecting data and analyzing data.

\subsection{Questionnaire Designing}

There are three types of questions, including 16 sub-questions.

The first type of questions is about the understanding and preference of the American animation image, the animation company, the designers and so on. The following are the specific questions and the answer options:

What are the famous American animated images that you know about? Options: MARVEL STUDIO, DC Comics, Warner Bros, Disney, and others. What are some famous animation characters do you know about? Options: the Aven- 
gers, Justice League, Mickey Mouse, Tom and Jerry, and others. What famous American animation designers do you know about? Options: Stan Lee, Jim Lee, Walt Disney, Joseph Barbera, and more. Which type of animation do you prefer? Options: cartoon, realistic, 20th, abstract, and others.

The second type is about buying animation products, such as the way of consumption and the frequency of consumption:

Through which way you buy these products? How much do you spend on this kind of products per year on average? What's your consumption frequency? What factors drive you to buy these products?

The third type is about the characteristic information of the questioner himself, including age, gender, profession, income, and nationality.

We designed the questionnaire based on the personal information of the questioner, to better analysis the relation between the preferences and the acknowledgements.

Through these questions, American animation companies can understand Chinese consumers more intuitively and deeply, thus producing better works and related products in order to expanding the market.

\subsection{Questionnaire}

Questionnaire Address: wenjuan.com. Collected time: Dec. 2017. Number of Questionnaires: 596 in total, 594 effective. Proportion of Jiangsu reached 49\%. Beijing the next, $8 \%$. Other refers to foreign countries, Hong Kong, China and Taiwan, China, $20 \%$.

\subsection{Data Analysis}

What are the famous American animated images that you know about? Figure 1 shows the statistical results of this problem.

How much do you spend on this kind of products per year on average? Figure 2 shows the statistical results of this problem.

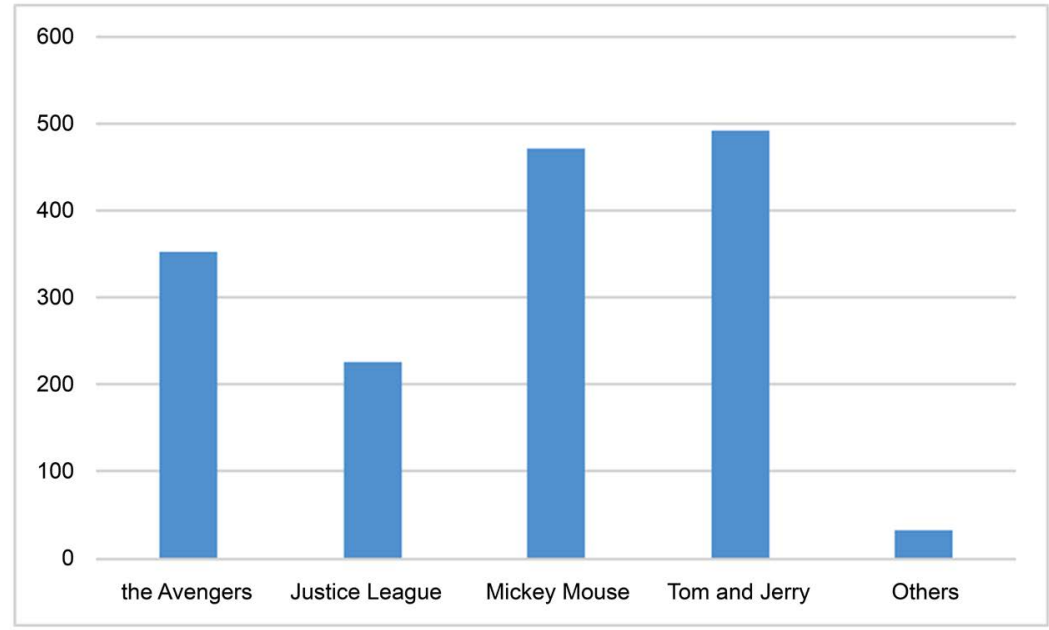

Figure 1. The first statistical chart. 


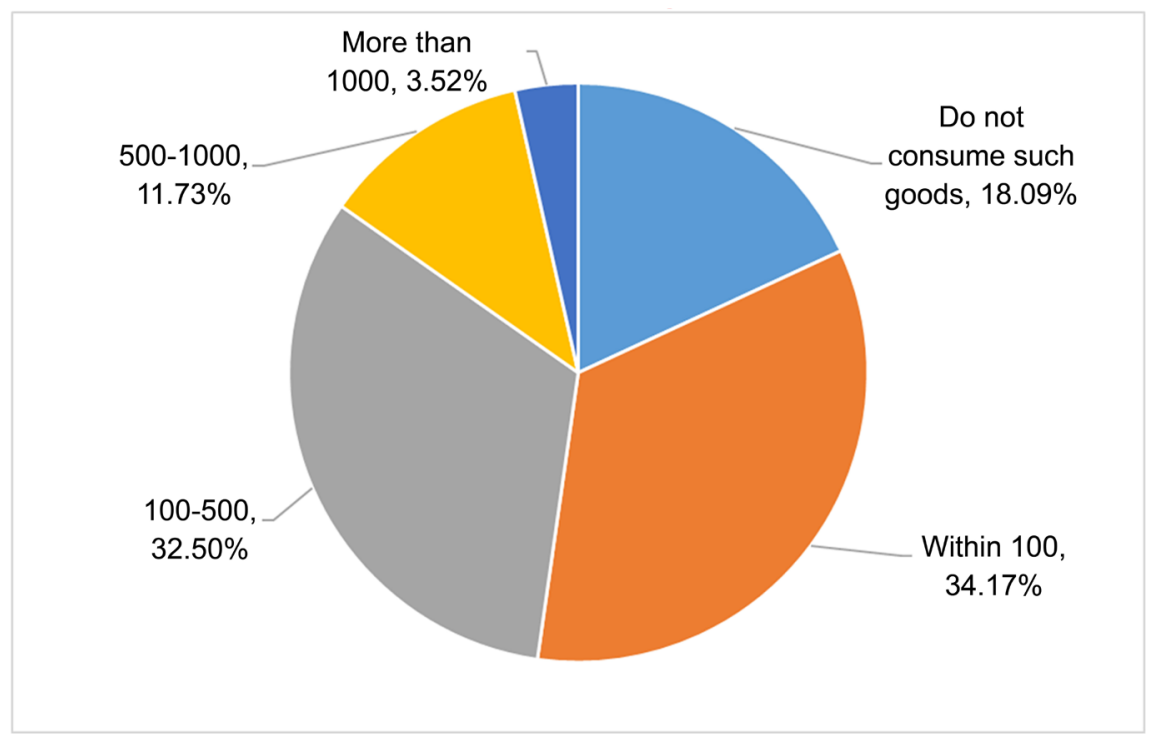

Figure 2. Second statistical charts.

\subsection{Topic Analysis}

1) People from different age groups: what do they know about American animation companies? Figure 3 shows the statistical results of this problem.

The Walt Disney Company was founded in 1926. Its main businesses include entertainment programs, theme parks, toys, books, video games and media. Marvel Comics was founded in 1939. Its main businesses include comic books, films and television, video games, toys and media. Marvel Comics is one of Disney's subsidiaries.

Disney's products are more popular considering consumers, not only the figures of science fiction superheroes, but also the more acceptable images of cartoon characters in fairy tales. I think the acceptable style of Disney's products makes it more favorable to the public. As a result, it can be concluded that older people are more aware of Disney rather than Marvel.

2) Gender and Comic styles

The results of the data analysis, as shown in Figure 4, demonstrate that women tend to be more inclined to abstract comic styles than men, while men tend to be more inclined to the style of realism.

Women prefer a virtual and idealistic style with a sense of perception. Men prefer the style of visual reality. According to psychological studies, visually, women first accept bright colors and perfect shapes. In this aspect, women tend to be illusory and imaginary. Men have no special preference for color, but focus on the plot or deeper meaning.

3) Income and Product selection

The results of this thematic analysis are shown in Figure 5. Zero income generally refers to the student group. They spend more on the figures. This group has no economic pressure, usually chooses according to their own preferences, and is more likely to be attracted by products produced on the basis of story plots. 


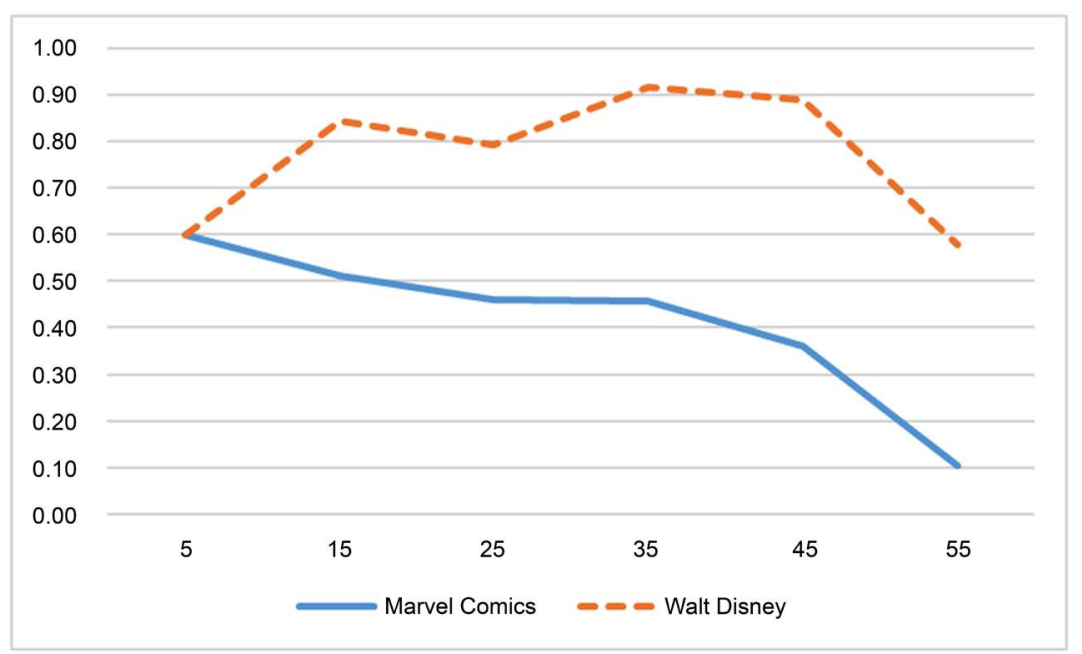

Figure 3. The first thematic analysis.

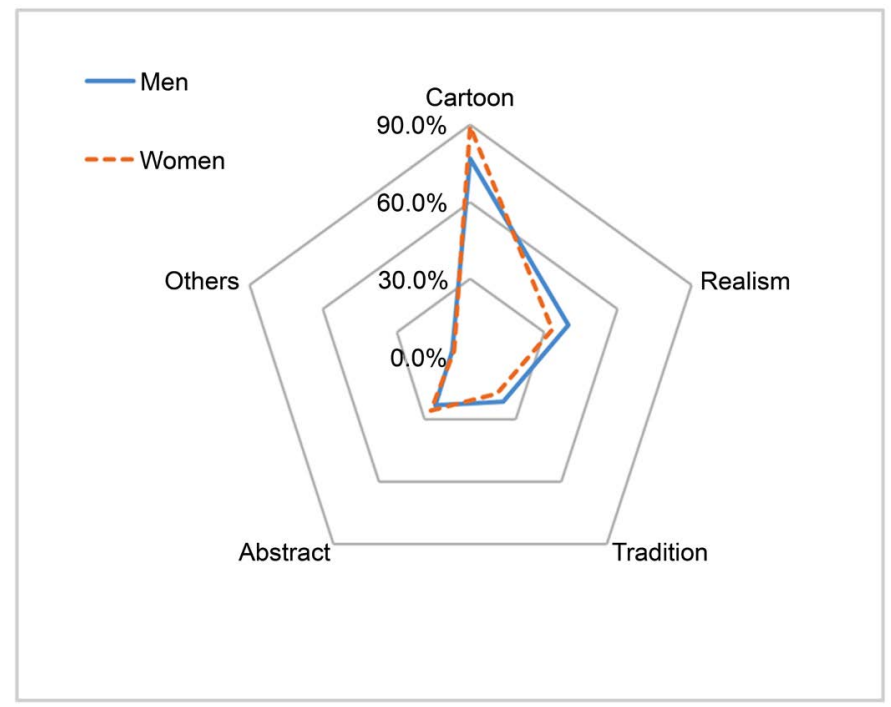

Figure 4. Second thematic analysis.

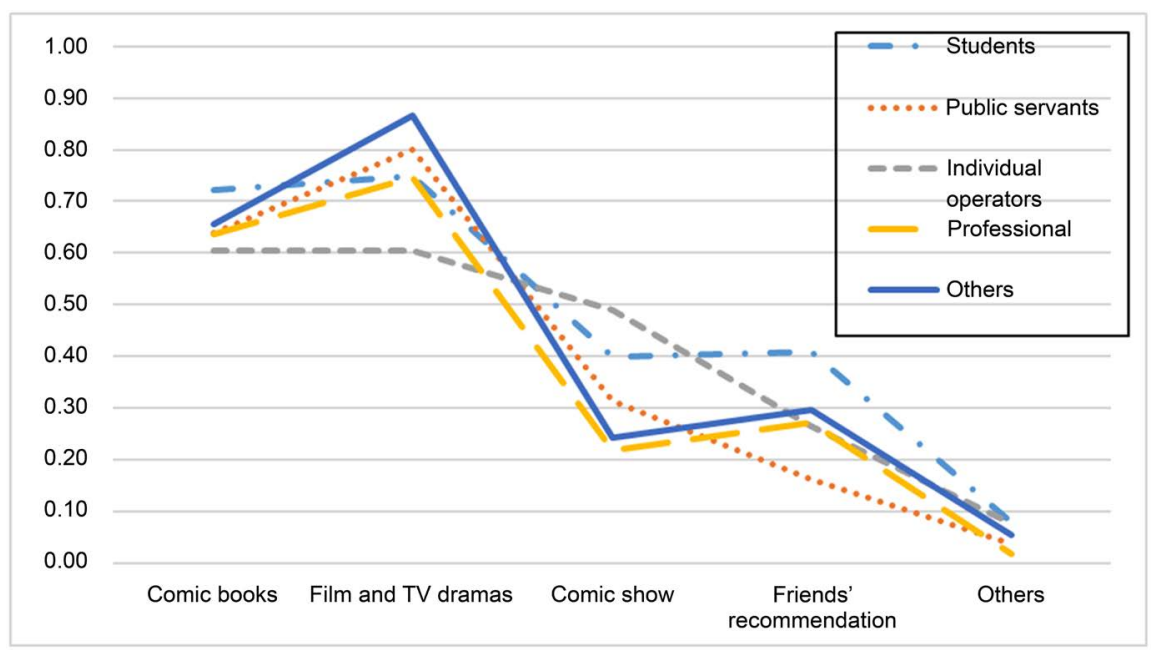

Figure 5. Third thematic analysis. 
The proportion of people who earn less than $1000 \mathrm{RMB}$ invests the highest proportion of comic books. When they make a choice, price is the primary consideration, so they are more inclined to cheap and good products.

The proportion of people whose income range from 1000 to $5000 \mathrm{RMB}$ invests in figures slightly more than that of other groups. Steady income makes them choose in favor of personal preferences.

The group with income from 5000 to $10000 \mathrm{RMB}$ has invested more in film and TV discs. The higher income of this group enables them to pay more attention to the experience and enjoyment of body and mind.

The group earning more than $10000 \mathrm{RMB}$ invests slightly more in other areas than other groups do. This aspect generally refers to the products of electronic technology, whose high income makes them capable to choose whatever they want, and pay more attention to the performance of products.

Today's society is in the Internet Era, and there are more and more people who choose to pay by credit card and Internet banking. According to expert analysis, the lower the payment transparency, the more money the consumer will spend.

Today's society is in the Internet Era, and there are more and more people who choose to pay by credit card and Internet banking. According to expert analysis, the lower the payment transparency, the more money the consumer will spend.

4) Profession and Ways to acknowledge

From Table 1 below, we can see that the proportion of students who get to know animation in the group is the highest compared to other groups through comic books and friends' recommendation. This group usually has limited time to use the Internet, consequently these two ways fill their demand in this area.

The two groups of public servants and other professions learn about animation in film and TV dramas better than other groups. Such groups have regular holidays, so that they can contact the Internet media more frequently.

Individual operators have more sufficient rest time and more stable income compared to other groups, so the comic show is a more suitable way for this group to learn about animation.

\section{Results \& Discussions}

Through this study, we get the conclusion that:

Table 1. Profession and Ways to acknowledge.

\begin{tabular}{cccccc}
\hline & Comic books & $\begin{array}{c}\text { Film and TV } \\
\text { dramas }\end{array}$ & $\begin{array}{c}\text { Comic } \\
\text { show }\end{array}$ & $\begin{array}{c}\text { Friends' } \\
\text { recommendation }\end{array}$ & Others \\
\hline Students & 0.72 & 0.75 & 0.40 & 0.41 & 0.08 \\
Public servants & 0.64 & 0.80 & 0.31 & 0.16 & 0.04 \\
Individual operators & 0.60 & 0.60 & 0.49 & 0.26 & 0.08 \\
Professional & 0.64 & 0.75 & 0.22 & 0.27 & 0.02 \\
Others & 0.66 & 0.87 & 0.24 & 0.30 & 0.05 \\
\hline
\end{tabular}


Different age groups have obvious differences in American animation preference or cognition (representative work, etc.). American animation companies can hold premieres, or designer signings, in China's main cities, so that more people will be acquainted with their influence in China.

Gender differences have effect on the preference of American animation style as well as its related products. American animation companies can design products that are more related to their preferences and expand their sales in the Chinese market according to gender.

Different professions understand American animation in different ways. In the current Information Era, the speed of network is absolutely predominant.

\section{Conclusion}

Through the questionnaire and data statistics (Questionnaire Website, Dec. 2017-Jan. 2018), this paper analyzes Chinese people's understanding of American animation. Data have discovered some points, such as: older people are more aware of Disney rather than Marvel. According to Figure 3, as people's age grows, the difference between their acknowledgements of animation companies is getting larger, sometimes reaches 50\%. Compared with other groups, students know more about American animation through comic books and friends' recommendation.

\section{Acknowledgements}

Thanks to Zou Xun, as well as Teacher Gao Haihong, for their help during the research.

\section{Conflicts of Interest}

The authors declare no conflicts of interest regarding the publication of this paper.

\section{References}

dcfiff3juv (2016). Research on the Origin and Development of Animation. http://www.360doc.com/content/16/0605/10/32759897_565184794.shtml

Gao, W. (2015). The Development of American Animation Industry and Its Enlightenment to China. Cinematic Literature, 17, 103-105.

Questionnaire Website (Dec. 2017-Jan. 2018). https://www.wenjuan.com/s/zeQjIf/

Shi, J. B., \& Wang, X. (2011). Exploring the Vitality of Chinese Animation Industry Based on American Animation Industry. Cinematic Literature, 06, 46-47.

$\mathrm{Xu}, \mathrm{Q}$. (2009). Review and Analysis of Successful Experience in American Animation Industry Chain. Popular Literature, 24, 58. 